\title{
Challenging diagnosis of congenital malaria in non-endemic areas
}

\author{
Lorenza Romani $^{1+} \mathbb{B}$, Stefania Pane ${ }^{2 \dagger}$, Carlo Severini ${ }^{3}$, Michela Menegon $^{3}$, Gianluca Foglietta ${ }^{2}$, \\ Stefania Bernardi ${ }^{1}$, Hyppolite K. Tchidjou ${ }^{1}$, Andrea Onetti Muda ${ }^{4}$, Paolo Palma ${ }^{1 *}$ and Lorenza Putignani $i^{2,5^{*} \ddagger}$
}

\begin{abstract}
Background: Congenital malaria is usually defined as the detection of asexual forms of Plasmodium spp. in a blood sample of a neonate during perinatal age if there is no possibility of postpartum infection by a mosquito bite. The incidence of congenital malaria is highly variable and seems related to several factors, such as different diagnostic methods for Plasmodium spp. detection, and area in which the epidemiologic analyses are performed. In nonendemic countries, cases of congenital malaria are rare. Hereby, a case of a congenital malaria in an HIV exposed child is reported.
\end{abstract}

Case presentation: A 2-month-old male child was admitted to Bambino Gesù Children's Hospital due to anaemia and exposure to HIV. He was born prematurely in Italy by cesarean section at 34 weeks' gestation after a bicorial, biamniotic pregnancy by a migrant woman from Nigeria. He was the first of non-identical twins. Combined with anaemia, spleen and liver enlargement was noted, malaria was hypothesized. Malaria laboratory panel was performed on the newborn, mother and other twin blood samples, as follows: (i) malaria rapid diagnostic test (RDT); (ii) Giemsa-stained thick and thin blood smears for Plasmodium spp. identification and parasitaemia titration; (iii) molecular screening and typing of Plasmodium spp. by multiplex qualitative PCR assay based on 185 rRNA gene. Genotyping of Plasmodium falciparum isolates from mother and child was performed by neutral microsatellite and highly polymorphic marker amplification.

Conclusions: The maternal RDT sample was negative, while the infant RDT was positive; in both cases microscopy of blood smears and PCR showed infection with P. falciparum. Two of the genotypic molecular markers displayed different allelic variants between the two samples. This difference could imply infection multiplicity of the mother during the pregnancy, possibly harbouring more than one isolate, only one of them being transmitted to the newborn while the other persisting in the mother's blood. Because of the increasing number of pregnant women coming from endemic areas for malaria, an accurate anamnesis of infant's mother, and the inclusion of Plasmodium spp. research into TORCH screenings for mother-infant pair at birth, aiming at reducing morbidity and mortality associated to the disease might be suitable.

Keywords: Congenital malaria, HIV, Bicorial, biamniotic pregnancy, Malaria laboratory panel, Plasmodium falciparum genotyping

\footnotetext{
*Correspondence: paolo.palma@opbg.net; lorenza.putignani@opbg.net

${ }^{\dagger}$ Lorenza Romani and Stefania Pane contributed equally to this work

‡Paolo Palma and Lorenza Putignani are shared last authors

${ }^{1}$ Division of Immunology and Infectious Diseases, Research Unit

in Congenital and Perinatal Infections, University-Hospital, Pediatric

Department (DPUO), Bambino Gesù Children's Hospital, Piazza

Sant'Onofrio 4, 00165 Rome, Italy

${ }^{2}$ Unit of Parasitology, Bambino Gesù Children's Hospital, Piazza

Sant'Onofrio 4, 00165 Rome, Italy

Full list of author information is available at the end of the article
}

(c) The Author(s) 2018. This article is distributed under the terms of the Creative Commons Attribution 4.0 International License (http://creativecommons.org/licenses/by/4.0/), which permits unrestricted use, distribution, and reproduction in any medium, provided you give appropriate credit to the original author(s) and the source, provide a link to the Creative Commons license, and indicate if changes were made. The Creative Commons Public Domain Dedication waiver (http://creativecommons.org/ publicdomain/zero/1.0/) applies to the data made available in this article, unless otherwise stated. 


\section{Background}

Congenital malaria is usually defined as the detection of asexual forms of Plasmodium spp. in a blood sample of a neonate during the first week of life or later if there is no possibility of postpartum infection by a mosquito bite (out of malaria endemic area) [1]. Congenital malaria can be acquired by transmission of parasites from the mother to child during pregnancy or perinatally during labour [2]. Congenital malaria in endemic countries is considered a rare condition due to the protective factors as the protection supplied by the placenta, the passive transfer of maternal antibodies [3] and the protective effect of fetal haemoglobin $[4,5]$. The incidence of congenital malaria is highly variable. The literature reported an incidence between 7 and 33\% in endemic area $[6,7]$ with an apparent increasing rate during the last years as result of rising drug resistance, increasing virulence of the parasite, human immunodeficiency virus (HIV) infection [7, 8]. The high variability seems related to several factors such as the different diagnostic methods and sampling (cord blood vs peripheral blood) used to detect Plasmodium spp., and the area in which the epidemiologic analyses are performed $[6,9]$. In non-endemic countries, cases of congenital malaria are rare: in Europe only one case of congenital Plasmodium falciparum malaria was reported in 2014 [10]; in the USA only 81 cases of congenital malaria were identified between the years 1966 and 2005 [11]. Hereby, the case of a congenital malaria in an HIV-exposed child is reported.

\section{Case presentation}

A 2-month-old male child was admitted to the Academic Department of Pediatrics of the Bambino Gesù Children's Hospital (BGCH) due to anaemia and exposure to HIV. He was born prematurely in Italy by cesarean section at 34 weeks' gestation after a bicorial, biamniotic pregnancy with birth weight of $2.080 \mathrm{~kg}$. He was the first of nonidentical twins. The mother was a 30 -year-old migrant woman from Nigeria, who arrived in Italy at 27 weeks gestation. At presentation, she tested seropositive for HIV and cytomegalovirus (CMV) and started antiretroviral therapy. Her absolute lymphocyte count was 1410/ $\mu \mathrm{l}$; CD4 count and the HIV viral load were not reported in the documentation received from the Hospital where the mother was admitted in emergency when she arrived in Italy.

The twins were tested for HIV at birth with PCR for HIV-RNA searching. The female twin was positive for HIV and CMV infection, while the male twin was HIV negative at birth and treated with zidovudin as postexposure prophylaxis for 6 weeks. TORCH screening (toxoplasmosis, rubella, cytomegalovirus, herpes simplex), abdominal and cerebral ultrasounds were performed to exclude other congenital infections on both twins. A week before admission at our Department the male twin was admitted to another hospital due to anaemia $(\mathrm{Hb} 5.1 \mathrm{~g} / \mathrm{dl})$, hence receiving a blood transfusion. On initial evaluation at $\mathrm{BGCH}$, he was in good general condition, weighed $3.910 \mathrm{~kg}$, with temperature of $36.5^{\circ} \mathrm{C}$, heart rate of 135 beats per minute, respiratory rate of 35 for minute. His abdomen was soft, the liver was palpable $4 \mathrm{~cm}$ below the right costal margin. The findings of the rest of the examination were unremarkable.

Laboratory tests at the admission, after a week from the first blood transfusion, revealed a leukocyte count of $12.000 / \mathrm{mm}^{3}$; a haemoglobin $(\mathrm{Hb})$ level of $9.1 \mathrm{~g} / \mathrm{dl}$; a platelet count of $198.000 / \mathrm{mm}^{3}$ and a reticulocyte count of $169.000 / \mathrm{mm}^{3}$. His bilirubin level was $1.31 \mathrm{~g} / \mathrm{dl}$ with direct bilirubin of $0.64 \mathrm{mg} / \mathrm{dl}$; lactate dehydrogenase level of $945 \mathrm{UI} / \mathrm{L}$ and normal renal and liver function values.

A myelosuppression effect due to the zidovudin was initially hypothesized, then the haemoglobin concentration was monitored and a supportive therapy with folic acid and iron per os was started.

During hospitalization, a progressive decrease of $\mathrm{Hb}$ levels to $6.8 \mathrm{~g} / \mathrm{dl}$ was observed, therefore, requiring additional blood transfusions. Causes of haemolytic anaemia and blood loss were excluded, due to persistently high reticulocyte count; also, direct and indirect Coombs and faecal occult blood tests were performed, resulting all of which were negative. Haemoglobin electrophoresis was also performed, although in the presence of blood transfusions, to exclude hereditary haemoglobinopathies. A subsequent physical examination was then performed, revealing an increase of spleen enlargement, also confirmed by ultrasound examination. A diagnostic of malaria was then considered.

Because of the infants' age and the origin of the mother who came from an endemic area for malaria, the malaria panel provided in $\mathrm{BGCH}$ was performed on twins and mother's blood. The panel included the following routine algorithm: (i) Rapid diagnostic test (RDT); (ii) microscopy of Giemsa-stained thick and thin blood smears for Plasmodium spp. identification (ID) and parasitaemia index assigned by two independent microscopists; (iii) molecular screening and typing of Plasmodium spp. by an end-point multiplex qualitative polymerase chain reaction $(\mathrm{PCR})$ assay.

The RDT, based on either Plasmodium spp. lactate dehydrogenase (pLDH) and P. falciparum histidine-rich protein 2 (HRP2) antigens, was performed by using SD Bioline Malaria Antigen P.f/Pan (Standard Diagnostic), whose performance is periodically monitored by the World Health Organization Malaria Control Programmes [12]. 
Briefly, about PCR assay, DNA was extracted from $200 \mu$ of EDTA blood with the QIAamp DNA Mini Kit (QIAGEN) and $5 \mu \mathrm{l}$ of each DNA sample were probed with the 18S rRNA gene target of the multiplex PCR STAT-NAT Malaria Screening and Typing (SentinelDiagnostics). PCR products were visualized using 2.2\% agarose (Lonza FlashGel ${ }^{\circledR}$ System) and a UV trans-illuminator BioRad.

The RDT for Plasmodium spp. was negative for mother and female infant specimens, while male infant resulted positive (Fig. 1). PCR analysis confirmed a positive result for mother and male twin, revealing a P. falciparum infection, while samples from the other twin were consistently negative with both techniques (Figs. 2, 3). Thick and thin blood films stained by Giemsa revealed trophozoite forms of $P$. falciparum with parasitaemia index of $1 \%$ for the male infant and $<1 \%$ for the mother. The RBCs of the mother infected with malarial parasites were of normal size and poly-parasitized by trophozoites (Fig. 4).

Genotyping of Plasmodium spp. isolates was carried out to identify infectious clones in both mother and infant. The genotyping was performed by amplification of a neutral microsatellite marker (MS-TA109) [13] and four highly polymorphic markers: $P$. falciparum merozoite surface protein 1 (Pfmsp1) and its allelic subfamilies (K1,

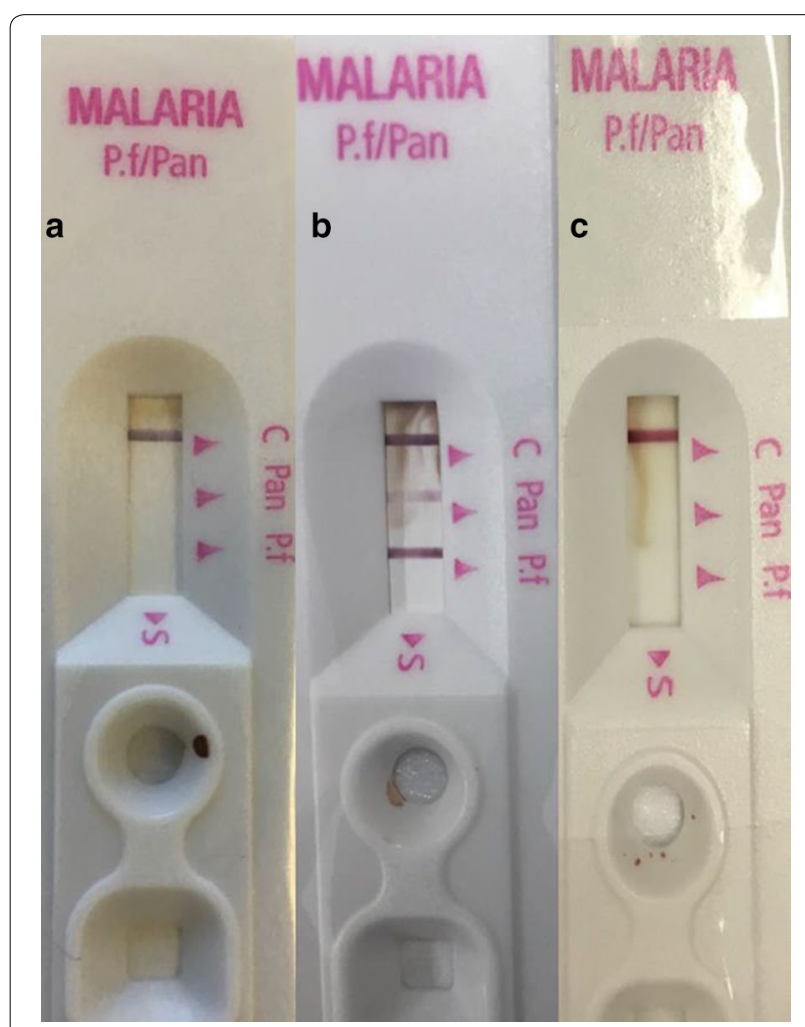

Fig. 1 Pattern of RDT for the mother (a), the male twin $(\mathbf{b})$, the female twin $(\mathbf{c})$

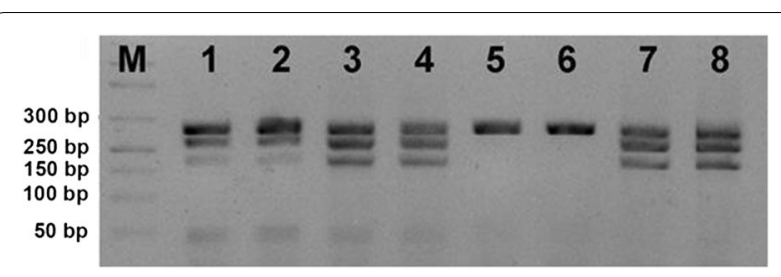

Fig. 2 Plasmodium spp. screening by $18 \mathrm{~S}$ rRNA targeting PCR. M DNA marker, (1/2) Mother's sample replicates; (3/4) male infant's sample replicates; (5/6) female infant's sample duplicates; (7/8) male infant's sample duplicates

RO33, MAD20) [14], P. falciparum merozoite surface protein 2 (Pfmsp2) and its allelic subfamilies (3D7, FC27) [14], P. falciparum histidine-rich protein 2 (Pfhrp2) and t P. falciparum histidine-rich protein 3 (Pfhrp3) [15]. For allele detections, PCR was done in a $25 \mu \mathrm{l} \mathrm{PCR} \mathrm{mix-}$ ture containing $10 \mu \mathrm{l}$ of extracted DNA, $1 \times$ of $\mathrm{MgCl}_{2}$ free buffer Fast Start Roche, $2 \mathrm{mM}$ of $\mathrm{MgCl}_{2}, 200 \mu \mathrm{M}$ of dNTPs, $10 \mu \mathrm{M}$ of each primer and $0.25 \mathrm{U}$ of FastStart Taq polymerase Roche. The cycling conditions for Pfmsp 1 were as follows: denaturation at $95^{\circ} \mathrm{C}$ for $5 \mathrm{~min}$, followed by 45 cycles at $94{ }^{\circ} \mathrm{C}$ for $30 \mathrm{~min}$, annealing at $47{ }^{\circ} \mathrm{C}$ for $45 \mathrm{~s}$ and extension at $72{ }^{\circ} \mathrm{C}$ for $1.5 \mathrm{~min}$ and a final extension at $72{ }^{\circ} \mathrm{C}$ for $5 \mathrm{~min}$. The cycling conditions for Pfmsp 1/Pfmsp 2 families were: $95{ }^{\circ} \mathrm{C}$ for $5 \mathrm{~min}$ followed by 45 cycles at $94{ }^{\circ} \mathrm{C}$ for $1 \mathrm{~min}, 55^{\circ} \mathrm{C}$ for $45 \mathrm{~s}, 72^{\circ} \mathrm{C}$ for $1.5 \mathrm{~min}$, and a final extension at $72{ }^{\circ} \mathrm{C}$ for $5 \mathrm{~min}$. The Pfhrp3 gene, FC27, K1 and TA109 microsatellites were amplified as described in Menegon et al. and Anderson et al. $[13,16]$. The amplification products were analysed using a high-resolution capillary electrophoresis (QIAxcel Advanced system, Qiagen).

Genotypic characterization of $P$. falciparum isolates showed the presence of a single isolate in each of the analysed blood samples. All five P. falciparum polymorphic markers were genotyped for isolate present in the newborn's infection, whereas only four markers (Ta109, Pfmsp1, Pfmsp2 and Pfhrp3) were successfully amplified for the maternal isolate. Both isolates belonged to the $\mathrm{K} 1$ and the FC27 allelic subfamilies. The comparison of allelic profiles, based on length polymorphism of analysed markers, showed dissimilar size alleles for two molecular markers, Pfmsp 2 and Pfhrp3, indicating that two different parasite isolates were present in the mother and child at the time of blood collection, 2 month after delivery. Moreover, the amplification failure of Pfhrp2 gene in the maternal sample was presumable due to the hrp2-deletion in the isolate infecting the mother (Fig. 5).

Because of the P. falciparum ID in the male infant, oral administration of atovaquone/proguanil $(125 \mathrm{mg} / 50 \mathrm{mg}$ daily for 3 days) was immediately started. The 


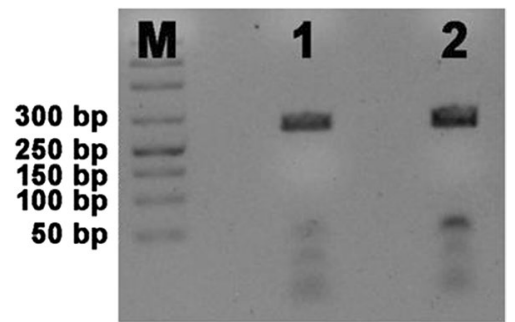

Fig. 3 Plasmodium falciparum typing by $18 \mathrm{~S}$ rRNA targeting PCR. M DNA marker, (1) Mother's sample; (2) male infant's sample

parasitaemia index on infant's blood performed after treatment confirmed the clearance of the parasites; the following blood exams revealed a normalization of $\mathrm{Hb}$ level.

\section{Discussion and conclusions}

This is the third case of congenital malaria ensued in a HIV-infected mother in a non-endemic country $[11,17]$. A review of congenital malaria cases in nonendemic country, by referring to a period spanning the last 40 years was included. The database mined for data searching was PubMed and the keywords used were "congenital malaria cases" and "non-endemic countries". The selected language was English. Congenital malaria is a rare disease in both non-endemic $[10,18]$ and endemic areas, the latter characterized by an incidence corresponding to $0.3-37 \%$ [19]. Among the 37 cases of congenital malaria in non-endemic country reported in the last 40 years, 21 (58\%) were caused by Plasmodium vivax, including 1 in combination with Plasmodium malariae and 1 with $P$. falciparum; 8 by $P$. falciparum (22\%); three cases caused by $P$. malariae and 2 by Plasmodium ovale (Table 1). Congenital malaria results from transplacental passage of parasites, which infect the infant in utero, or during delivery. Different mechanisms have been postulated: maternal transfusion into the fetal circulation, direct penetration of parasite through the chorionic villi or through premature separation of placenta [1]. Rarely, maternal history of malaria may not be reported and, therefore, it cannot be considered as a criterion for the diagnosis of congenital malaria [17]. Origin from endemic countries for malaria, fever during pregnancy, placental malaria and anaemia in the mother, are the main risk factors $[1,8]$.

HIV infection increases susceptibility to malaria during pregnancy [7] and it is associated with higher parasite density, higher risk of maternal and fetal anaemia, intra-uterine growth retardation (IUGR) and pre-term delivery [20], and low birth weight (LBW) in the neonates [21]. Recently a higher prevalence of congenital malaria in infants of mothers co-infected with HIV and
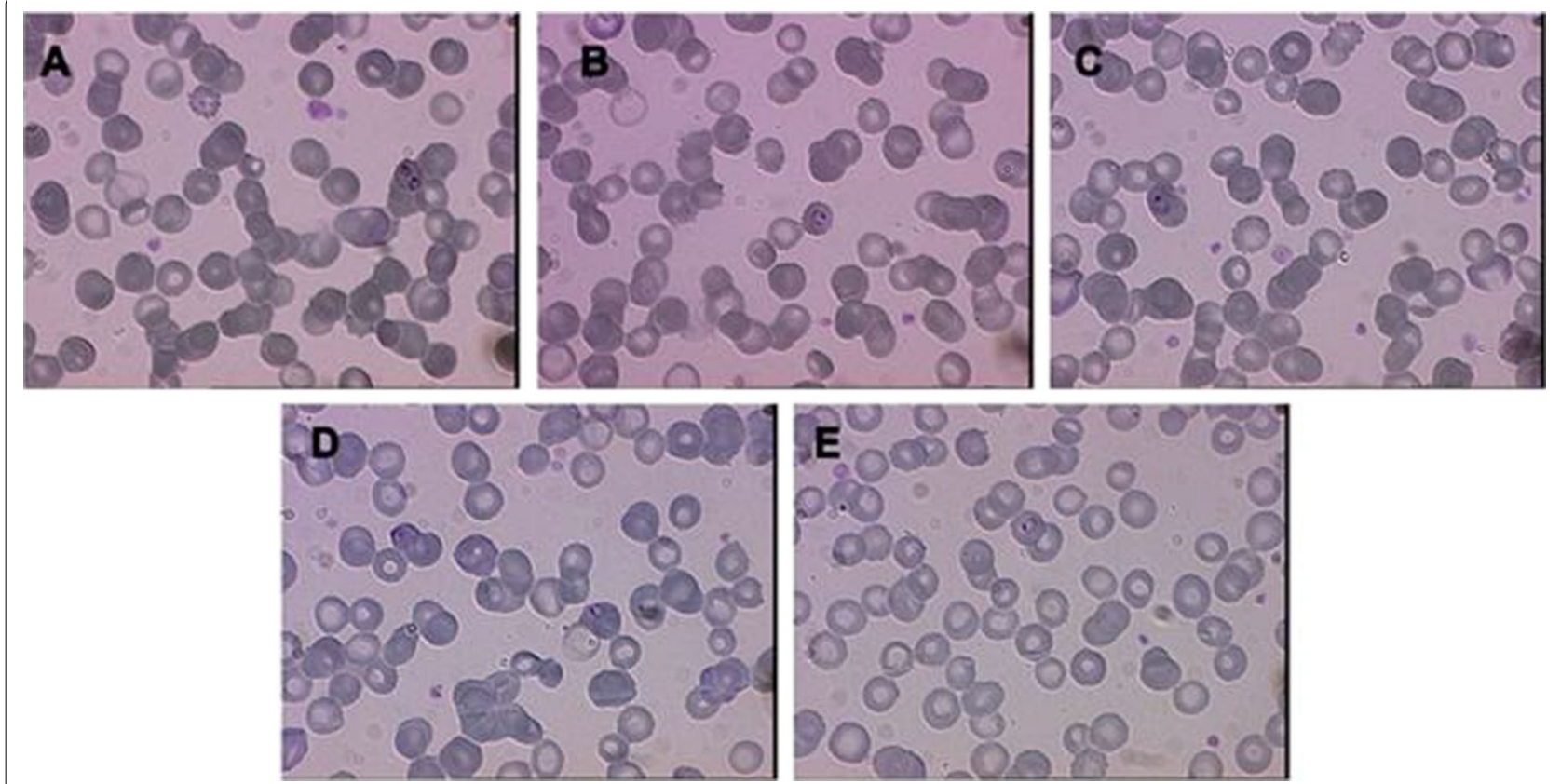

Fig. 4 Infant and maternal blood smears. A-C Mother's thin blood smear revealing P. falciparum immature trophozoites (ring forms) within erythrocytes. D, E Infant's thin blood smear, obtained on the day of delivery, documenting the presence of $P$. falciparum trophozoites within erythrocytes 


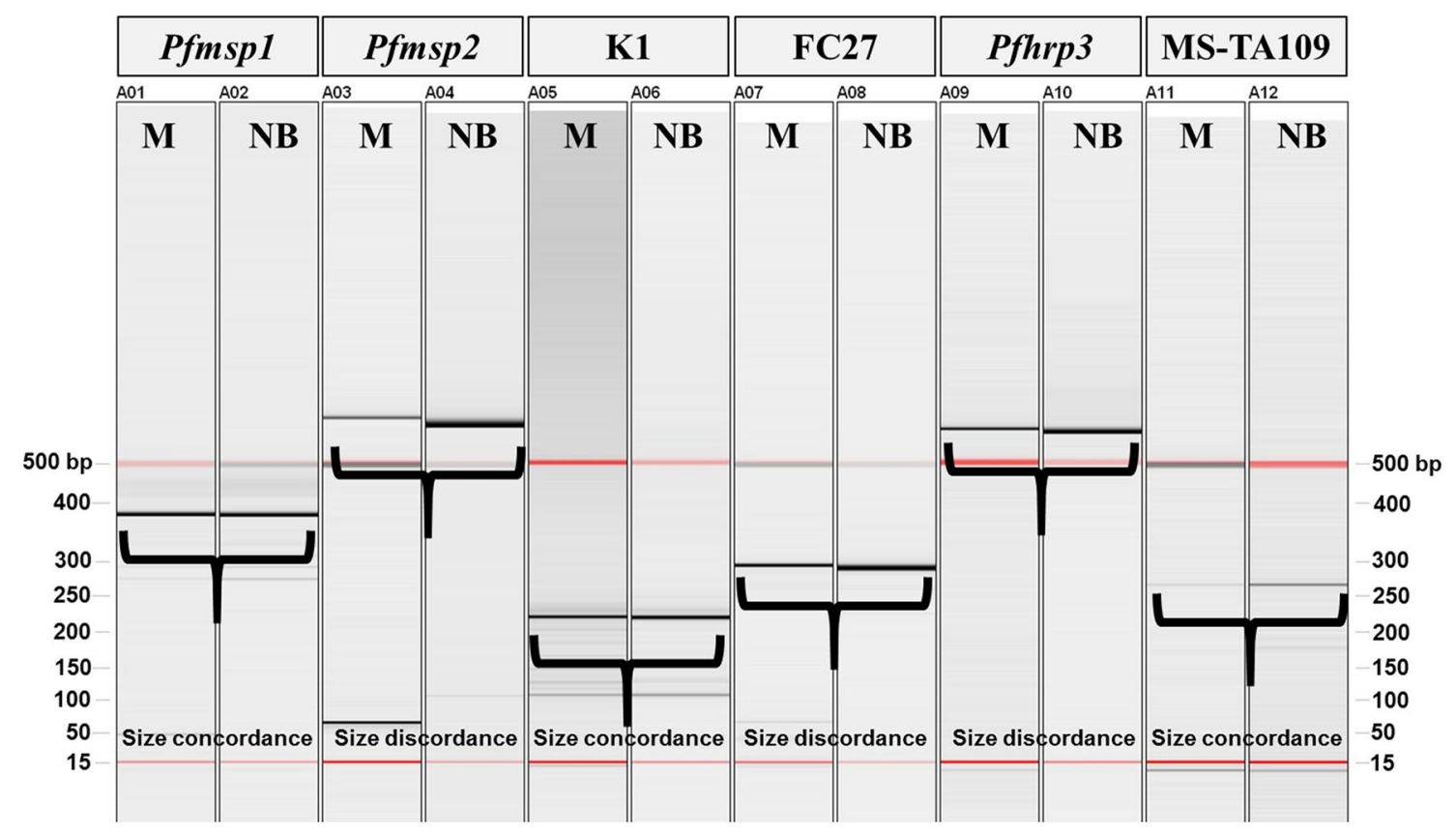

Fig. 5 Electronic image of the gel displaying PCR product sizes of the six molecular markers amplified from mother and newborn DNA samples. The markers Pfmsp2, FC27 (subfamily of Pfmsp2) and Pfhrp3 showed discordant genotypes between the two analyzed samples

malaria have been reported [8]. HIV infection compromised maternal immunity though an impairment of antibody responses with a higher risk of $P$. falciparum transmission [22]. However, the mechanism by which HIV increases susceptibility to malaria is not known. After birth, the mother may have a normal physical examination and negative blood malaria parasite [17]. In the present case, the mother never suffered from fever or symptoms suggestive for malaria during pregnancy. In women from endemic countries for malaria and with previous episodes of malaria it is common to be asymptomatic because of the immunity developed during the time [23].

In most cases of congenital malaria, the diagnosis is made at 10-28 days of age; 20 of the 37 published cases (56\%) were diagnosed before 21 days (Table 1 ). The symptoms are rarely detected at birth, possibly because of the presence of IgG transferred from the mother during the pregnancy, and the protective effect of $\mathrm{HbF}$; indeed, the passive immunity may prevent delay the onset of congenital malaria up to 6 weeks [24].

Clinical features of congenital malaria include fever, anaemia, thrombocytopaenia, liver and spleen enlargement. Jaundice, regurgitation, loose stools and poor feeding, occasionally apnea and cyanosis have also been reported [1]. Such clinical features may be confused with bacterial or viral infection, leading to a delay in diagnosis
[25]. The patient presented anaemia with high level of reticulocyte. He needed a blood transfusion every week, a progressive spleen enlargement was noted. Initially toxicity by antiretroviral therapy was hypothesized because of the good clinical condition and the absence of symptoms and signs suggestive for infection. No fever was detectable during the entire hospitalization. Five other cases of congenital malaria without fever have been described (Table 1). In this case, there was not record of the exact onset of anaemia because blood tests were not performed during the period 7-30 days after birth. Likely, the anaemia occurred days and even weeks before admission to hospital.

The mother of the infant travelled during pregnancy in region where a high percentage of $P$. falciparum chloroquine resistance is reported, finally arriving to a nonendemic country [26, 27]. Because of the stable clinical condition and for the suspect of chloroquine resistance, the authors decided to treat the infant, with atovaquone/ proguanil according to CDC guidelines [28]. Because the parasitaemia index was $1 \%$ and no criteria of severe malaria were present, oral administration was considered as appropriate treatment. Plasmodium spp. on female twin's blood was absent, as reported for other cases in the literature [29-36]. Peripheral maternal and peripheral newborn's parasite populations was analysed 2 month after delivery to compare allelic profile of persistent $P$. 


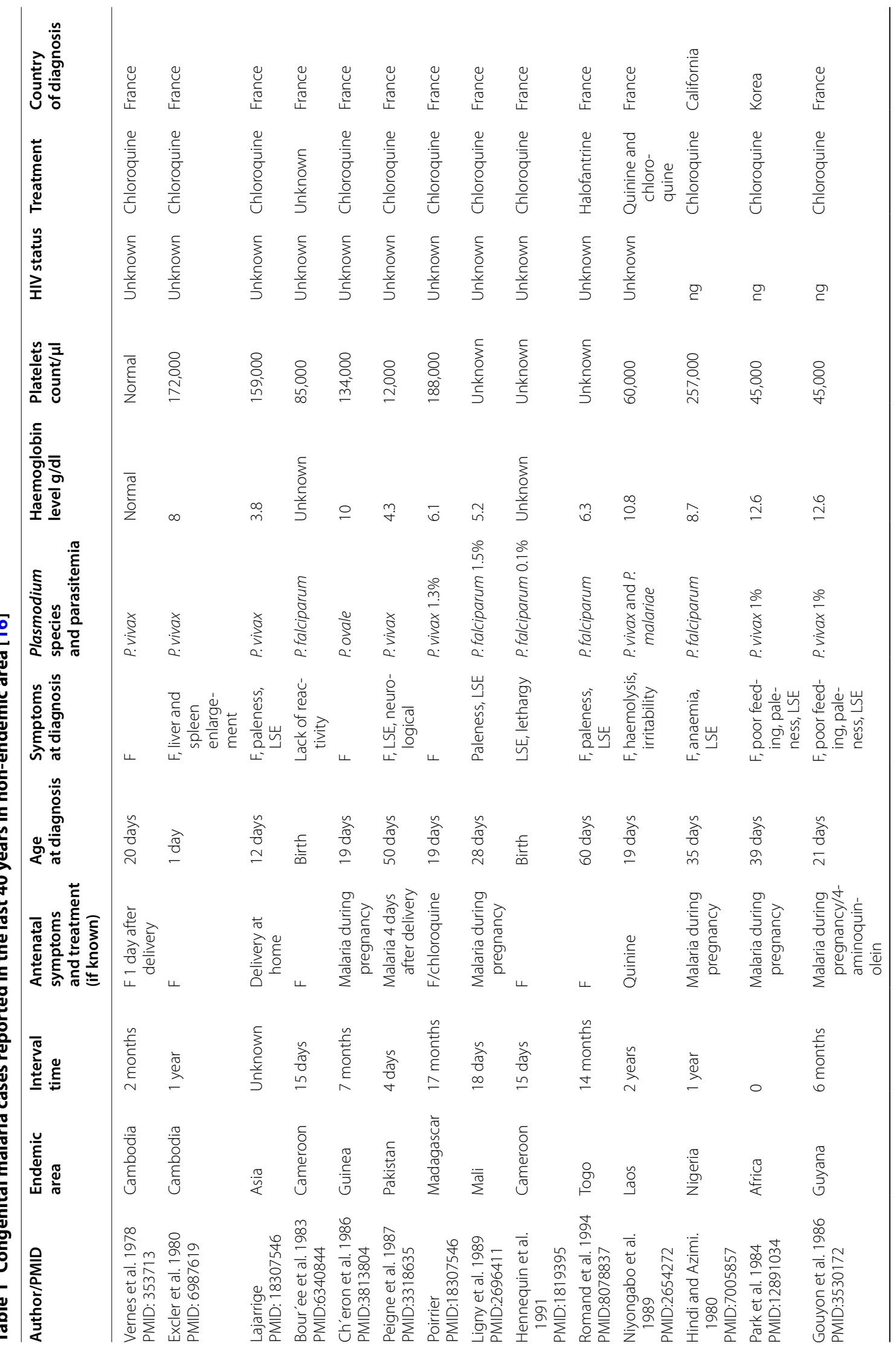




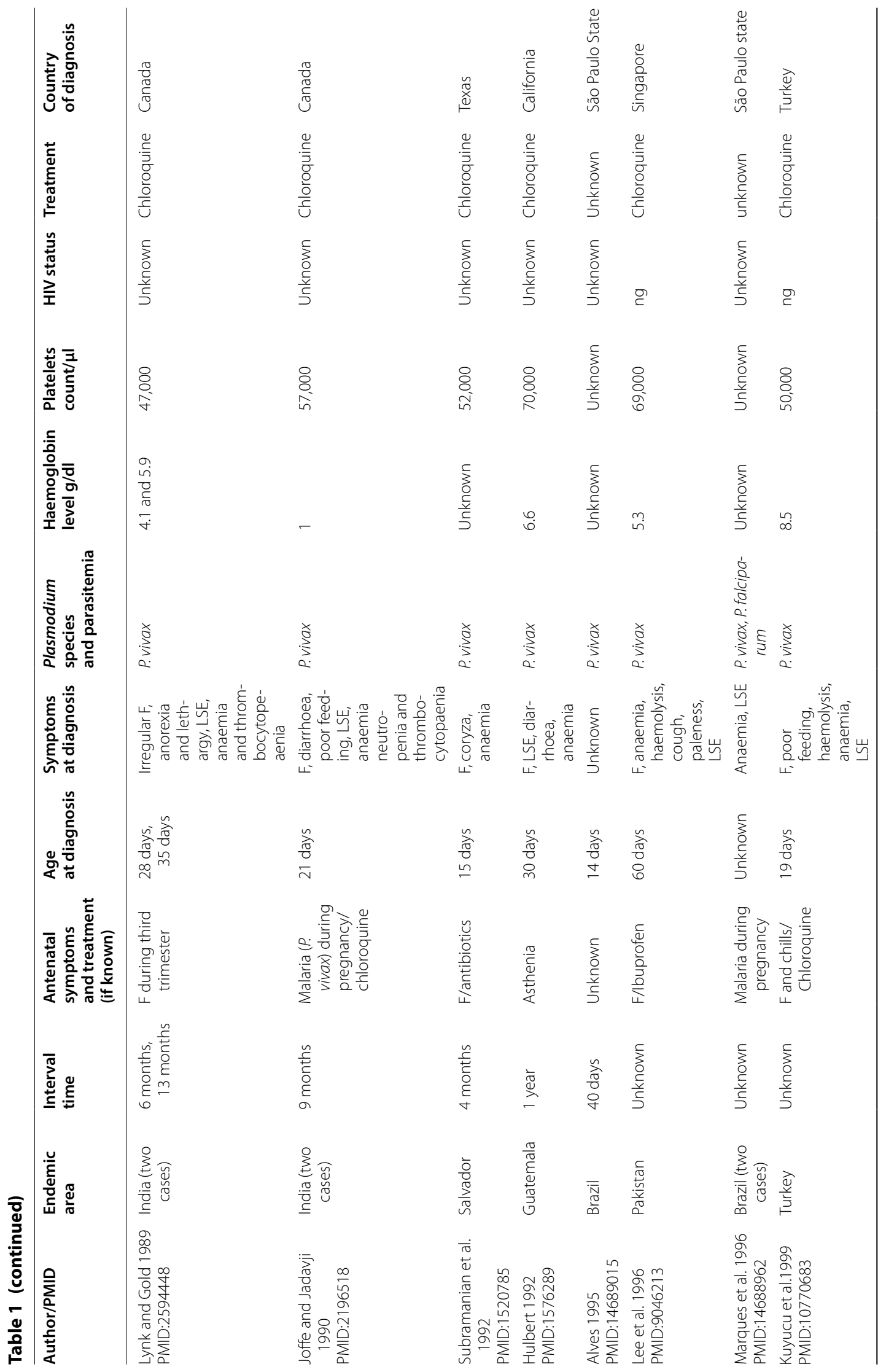




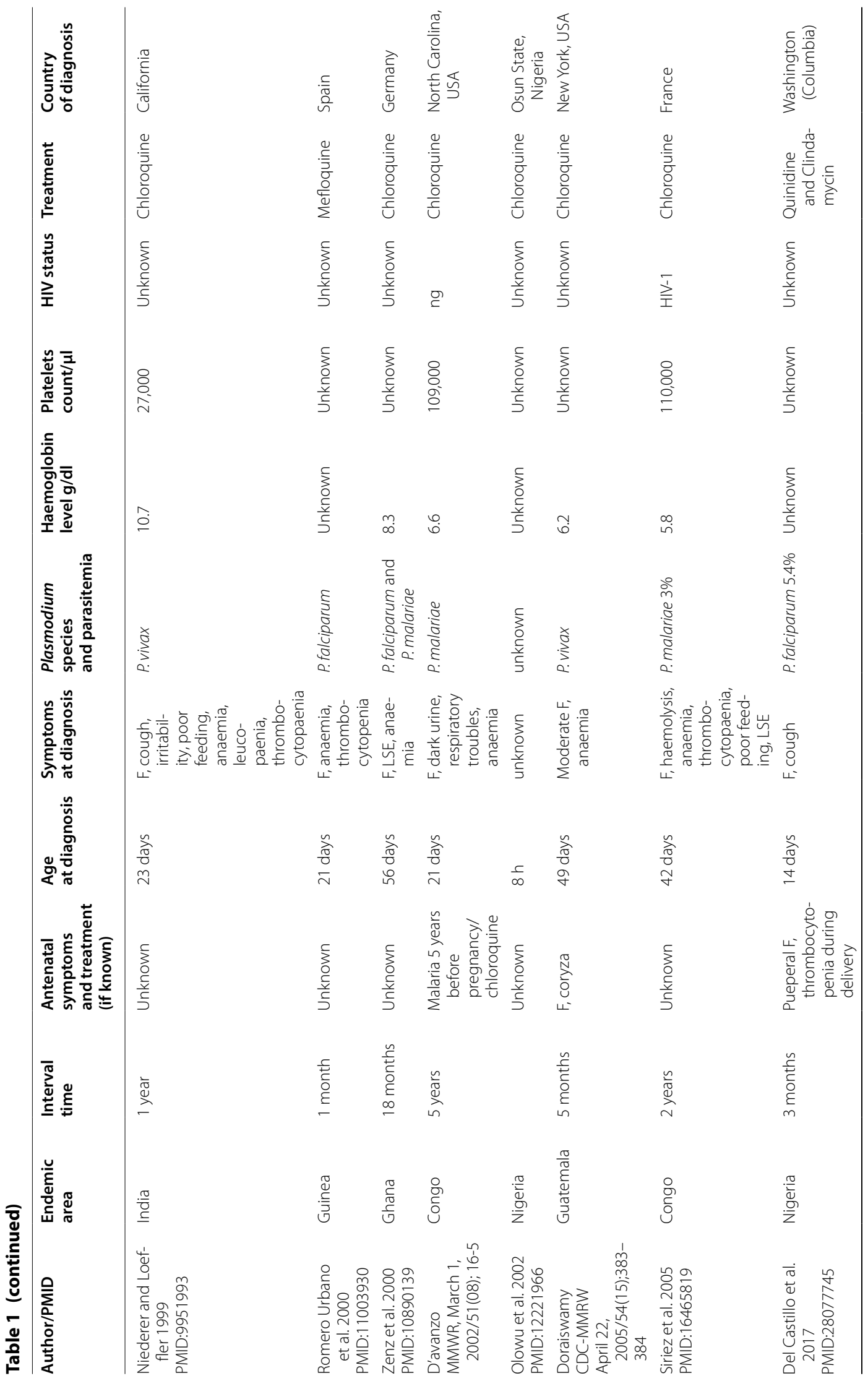




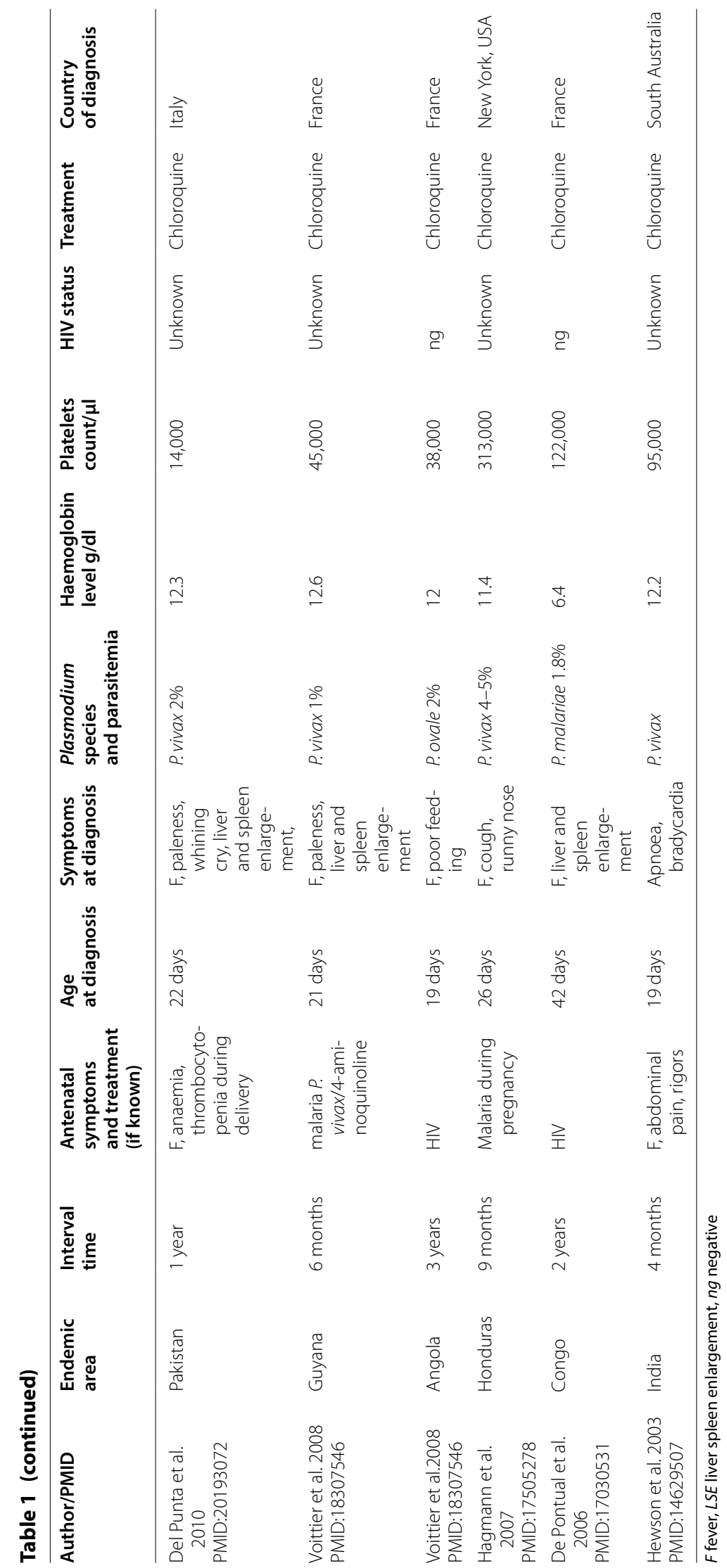


falciparum isolates. Two different parasite isolates in the mother and child at the time of blood collection were found. Likely during the gestation the mother was parasitized by different $P$. falciparum strains, as supported by literature data [37]. It is conceivable for the mother to have harboured more than one isolate during pregnancy, only one of them being transmitted to the newborn and the different one having persisted in the mother's blood after delivery [38].

Malaria RDTs are useful tools to confirm presence of malaria. Under optimal conditions, the sensitivity of the RDTs is considered similar to that of direct microscopy [39]. However, their execution may be questionable since on a number of occasions false negative results have been encountered which would negatively affect proper early therapeutic intervention. The three main groups of antigens detected by RDTs are HRP2, produced by trophozoites and young gametocytes of $P$. falciparum only; pLDH enzyme ( $P$. falciparum specific, $P$. vivax specific or pan specific), and aldolase pan-specific enzyme [40].

In the presented case, RDTs of peripheral blood failed to detect a maternal infection, while PCR and microscopy were highly effective. PfHRP2 is a histidine and alanine-rich protein, characterized by a highly polymorphic repeat domain and represents the most common malaria antigen targeted by RDTs for the specific diagnosis of $P$. falciparum [41]. Frequently, another protein of $P$. falciparum, the PfHRP3 antigen [42], is recognized by PfHRP2based RDTs $[40,43]$. The above studies further revealed that polymorphisms of the Pfhrp $2 / 3$ genes can affect the performance of HRP2-based RDTs in term of sensitivity up to total test failure (false-negative), recommending molecular investigation. False negatives can be also due to impairment in host and parasite density, or antigen concentration.

Finally, P. falciparum parasites not expressing PfhHRP2 and/or PfHRP3 antigens have been reported [44]. These results are consistent with those reported in the literature [45-49], and suggest that diagnostic guidelines for malaria be revisited.

The negative RDT in the mother can be justified by a low parasitaemia index and by the possible deletion of the Pfhrp 2 gene in this parasite. As in the present case, the discordance in vertical transmission of malaria in bicorial and biamniotic pregnancy is reported in the literature [29], as well for CMV, HIV and toxoplasmosis $[32,33,35]$. Therefore, the same pathogenesis was supposed for the present case.

\section{Conclusion}

A prompt diagnosis of congenital malaria is crucial. The increasing number of pregnant women travelling from endemic areas for malaria to non-endemic countries, calls for routine investigation of Plasmodium spp. in women and neonates at risk: (i) women and pregnant women from endemic area for malaria, (ii) all neonates and infants with fever, anaemia, thrombocytopaenia and hepatosplenomegaly with mother who have travelled or lived in non-endemic area for malaria (Fig. 6).

In such cases, accurate anamnesis of neonate's mother and inclusion of Plasmodium spp. search into the TORCH screening for mother and infant at birth should be performed, to avoid delay in the diagnosis and to reduce morbidity and mortality associated to

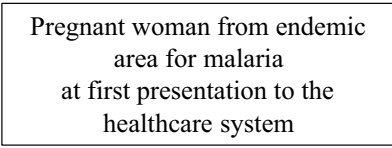
Pregnant woman from endemic area for malaria, first presentation at point of labour

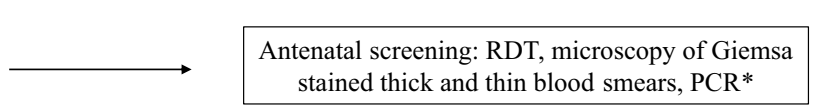

RDT, microscopy of Giemsa stained thick and thin blood smears on woman's blood and cord blood and PCR*

RDT, microscopy of Giemsa stained thick, thin blood smears and $\mathrm{PCR}^{*}$ on neonate's blood

RDT, microscopy of Giemsa stained, thick and thin blood smears and PCR* on neonate's blood

Fig. 6 Hypothesis of diagnostic algorithm for congenital malaria. Asterisk If PCR for Plasmodium spp is available in the Hospital 
the disease. The differential diagnosis between neonatal malaria vs neonatal sepsis is not easily to be resolved by the use of clinical features alone. However, also the laboratory diagnosis of low parasitaemia, such as that observed in mother-infant pair infections, require high level of expertise in malaria diagnostic panels. Use of malaria RDT assays that can detect antigens other than PfHRP2 and pLDH should could be strongly encouraged in field setting but also in hospitals, in order to enhance malaria diagnosis. Advanced malaria diagnostic panels, when possible, can be decisive to monitor both congenital and other malaria infections during perinatal and paediatric ages.

\begin{abstract}
Abbreviations
HIV: human immunodeficiency virus; TORCH: toxoplasmosis, rubella, cytomegalovirus, herpes simplex; RDT: rapid diagnostic test; LDH: lactate dehydrogenase; hrp2: histidine-rich protein 2; MS-TA109: microsatellite-(TA)n; Pfmsp 1: Plasmodium falciparum merozoite surface protein 1; Pfmsp2: Plasmodium falciparum merozoite surface protein 2; Pfhrp3: Plasmodium falciparum histidinerich protein 3; LBW: low birth weight; IUGR: intra-uterine growth retardation; WHO: World Health Organization.
\end{abstract}

\section{Authors' contributions}

All authors have made substantial contributions to the investigations presented in this manuscript. PP and LP made the diagnosis, supervised all data collection and participated in drafting the manuscript; LR drafted the manuscript; SB, PP and HT clinically followed-up the mother and the child, SP, MM, GF, LP and CS carried out the molecular and genotyping studies. SP, SB, $\mathrm{MM}, \mathrm{CS}, \mathrm{HT}$ and $\mathrm{AOM}$, revised the manuscript. All authors read and approved the final manuscript.

\begin{abstract}
Author details
1 Division of Immunology and Infectious Diseases, Research Unit in Congenital and Perinatal Infections, University-Hospital, Pediatric Department (DPUO), Bambino Gesù Children's Hospital, Piazza Sant'Onofrio 4, 00165 Rome, Italy. ${ }^{2}$ Unit of Parasitology, Bambino Gesù Children's Hospital, Piazza Sant'Onofrio 4, 00165 Rome, Italy. ${ }^{3}$ Istituto Superiore di Sanità (ISS), Viale Regina Elena 299, 00161 Rome, Italy. ${ }^{4}$ Department of Laboratories, Bambino Gesù Children's Hospital, Piazza Sant'Onofrio 4, 00165 Rome, Italy. ${ }^{5}$ Unit of Human Microbiome, Bambino Gesù Children's Hospital, Viale San Paolo 15, 00146 Rome, Italy.
\end{abstract}

\section{Acknowledgements}

We want to thank the patient who participated in this study, and the staff of Fondazione Siniscalco Ceci Emmaus Onlus. We thank Valeria Marzano for advice in figure preparation.

\section{Competing interests}

The authors declare that they have no competing interests.

\section{Availability of data and materials}

Upon request emoscopic and DNA materials are available.

\section{Consent for publication}

A copy of the written consent is available for review by the Editor-in-Chief of this journal.

\section{Ethics approval and consent to participate}

Written informed consent was obtained from the mother for her participation and that of her baby for the publication of this case report.

\section{Funding}

This study was supported by internal grant from "Bambino Gesù Children's Hospital" (RC 2018) to Paolo Palma and by CCM 2015 AMR to Lorenza
Putignani (http://www.ccm-network.it/pagina.jsp?id=node/2075\&idP $=740 \&$ $\mathrm{idF}=1870)$.

\section{Publisher's Note}

Springer Nature remains neutral with regard to jurisdictional claims in published maps and institutional affiliations.

Received: 24 July 2018 Accepted: 5 December 2018

Published online: 14 December 2018

\section{References}

1. Menendez C, Mayor A. Congenital malaria: the least known consequence of malaria in pregnancy. Semin Fetal Neonatal Med. 2007;12:207-13.

2. D'Alessandro U, Ubben D, Hamed K, Ceesay SJ, Okebe J, Taal M, et al. Malaria in infants aged less than six months-is it an area of unmet medical need? Malar J. 2012;11:400.

3. Cohen S, McGregor IA, Carrington S. Gamma-globulin and acquired immunity to human malaria. Nature. 1961;192:733-7.

4. Billig EM, McQueen PG, McKenzie FE. Foetal haemoglobin and the dynamics of paediatric malaria. Malar J. 2012;11:396.

5. Shear HL, Grinberg L, Gilman J, Fabry ME, Stamatoyannopoulos G, Goldberg DE, et al. Transgenic mice expressing human fetal globin are protected from malaria by a novel mechanism. Blood. 1998;92:2520-6.

6. Falade C, Mokuolu O, Okafor H, Orogade A, Falade A, Adedoyin O, et al. Epidemiology of congenital malaria in Nigeria: a multi-centre study. Trop Med Int Health. 2007;12:1279-87.

7. Desai M, ter Kuile FO, Nosten F, McGready R, Asamoa K, Brabin B, et al. Epidemiology and burden of malaria in pregnancy. Lancet Infect Dis. 2007;7:93-104.

8. Eki-Udoko FE, Sadoh AE, Ibadin MO, Omoigberale Al. Prevalence of congenital malaria in newborns of mothers co-infected with HIV and malaria in Benin city. Infect Dis (Lond). 2017;49:609-16.

9. Carlier Y, Truyens C, Deloron P, Peyron F. Congenital parasitic infections: a review. Acta Trop. 2012;121:55-70.

10. European Centre for Disease Prevention and Control. Annual epidemiological report 2016. 2014 data. https://ecdc.europa.eu/en/publicationsdata/malaria-annual-epidemiological-report-2016-2014-data. Accessed 19 Nov 2015.

11. Del Castillo M, Szymanski AM, Slovin A, Wong EC, DeBiasi RL. Congenital Plasmodium falciparum malaria in Washington, DC. Am J Trop Med Hyg. 2017:96:167-9.

12. Malaria rapid diagnostic test performance: results of WHO product testing of malaria RDTs: round 6. 2014-2015. http://www.who.int/malaria/ publications/atoz/9789241510035/en/. Accessed Dec 2015.

13. Anderson TJ, Su XZ, Bockarie M, Lagog M, Day KP. Twelve microsatellite markers for characterization of Plasmodium falciparum from finger-prick blood samples. Parasitology. 1999;1 19:113-25.

14. Soulama I, Nébié I, Ouédraogo A, Gansane A, Diarra A, Tiono AB, et al. Plasmodium falciparum genotypes diversity in symptomatic malaria of children living in an urban and a rural setting in Burkina Faso. Malar J. 2009:8:135.

15. Baker J, McCarthy J, Gatton M, Kyle DE, Belizario V, Luchavez J, et al. Genetic diversity of Plasmodium falciparum histidine-rich protein 2 (PfHRP2) and its effect on the performance of PfHRP2-based rapid diagnostic tests. J Infect Dis. 2005;192:870-7.

16. Menegon M, L'Episcopia M, Nurahmed AM, Talha AA, Nour BYM, Severini C. Identification of Plasmodium falciparum isolates lacking histidine-rich protein 2 and 3 in Eritrea. Infect Genet Evol. 2017;55:131-4.

17. Vottier G, Arsac M, Farnoux C, Mariani-Kurkdjian P, Baud O, Aujard Y. Congenital malaria in neonates: two case reports and review of the literature. Acta Paediatr. 2008;97:505-8.

18. Prior AR, Prata F, Mouzinho A, Marques JG. Congenital malaria in a European country. BMJ Case Rep. 2012. https://doi.org/10.1136/bcr-2012007310.

19. Olupot-Olupot P, Eregu EIE, Naizuli K, Ikiror J, Acom L, Burgoine K. Neonatal and congenital malaria: a case series in malaria endemic eastern Uganda. Malar J. 2018;17:171. 
20. Moya- Alvarez V, Abellana R, Cot M. Pregnancy-associated malaria and malaria in infants: an old problem with present consequences. Malar J. 2014;13:271.

21. ter Kuile FO, Parise ME, Verhoeff FH, Udhayakumar V, Newman RD, van Eijk AM, et al. The burden of co-infection with human immunodeficiency virus type 1 and malaria in pregnant women in sub-Saharan Africa. Am J Trop Med Hyg. 2004;71(2 Suppl):41-54.

22. Naniche D, Serra-Casas E, Bardají A, Quintó L, Dobaño C, Sigauque B, et al. Reduction of antimalarial antibodies by HIV Infection is associated with increased risk of Plasmodium falciparum cord blood infection. J Infect Dis. 2012;205:568-77.

23. Rogerson SJ, Hviid L, Duffy PE, Leke RF, Taylor DW. Malaria in pregnancy: pathogenesis and immunity. Lancet Infect Dis. 2007;7:105-17.

24. Mohan K, Omar BJ, Singh RD, Maithani MM, Chaurasia RN. Clinico-hematological features and management outcome in neonatal malaria: a nine years analysis from North India. Curr Pediatr Rev. 2016;12:286-91.

25. Del Punta V, Gulletta M, Matteelli A, Spinoni V, Regazzoli A, Castelli F. Congenital Plasmodium vivax malaria mimicking neonatal sepsis: a case report. Malar J. 2010;9:63.

26. Hagmann S, Khanna K, Niazi M, Purswani M, Robins EB. Congenital malaria, an important differential diagnosis to consider when evaluating febrile infants of immigrant mothers. Pediatr Emerg Care. 2007;23:326-9.

27. Wellems TE, Plowe CV. Chloroquine-resistant malaria. J Infect Dis. 2001;184:770-6.

28. Centers for Disease control and Prevention CDC. Treatment of malaria (guidelines for clinicians). 2013. https://www.cdc.gov/malaria/resources/ pdf/clinicalguidance. Accessed July 2013.

29. Balatbat $A B$, Jordan GW, Halsted C. Congenital malaria in a nonidentical twin. West J Med. 1995;162:458-9.

30. Linden WV, Linden HV Jr, Leal MC, Rolim Filho EL, Linden AV, Aragão MFVV, et al. Discordant clinical outcomes of congenital Zika virus infection in twin pregnancies. Arq Neuropsiquiatr. 2017;75:381-6.

31. Lazzarotto T, Gabrielli L, Foschini MP, Lanari M, Guerra B, Eusebi V, et al. Congenital cytomegalovirus infection in twin pregnancies: viral load in the amniotic fluid and pregnancy outcome. Pediatrics. 2003;112:e153-7.

32. Thapa R, Banerjee P, Akhtar N, Jain TS. Discordance for congenital toxoplasmosis in twins. Indian J Pediatr. 2009;76:1069-70.

33. de Martino M, Tovo PA, Galli L, Caselli D, Gabiano C, Mazzoni PL, et al. HIV-I infection in perinatally exposed siblings and twins: the Italian register for HIV infection in children. Arch Dis Child. 1991;66:1235-8.

34. Barlow KM, Mok JY. Dizygotic twins discordant for HIV and hepatitis C virus. Arch Dis Child. 1993;68:507.

35. Egaña-Ugrinovic G, Goncé A, García L, Marcos MA, López M, Nadal A, et al. Congenital cytomegalovirus infection among twin pairs. J Matern Fetal Neonatal Med. 2016;29:3439-44.

36. Tomasik T, Zawilińska B, Pawlik D, Ferek J, Ferek J, Wójtowicz A, et al. Congenital cytomegaly in one twin: a case report. Med Wieku Rozwoj. 2012;16:252-60.
37. Mwangoka GW, Kimera SI, Mboera LE. Congenital Plasmodium falciparum infection in neonates in Muheza District, Tanzania. Malar J. 2008;7:117.

38. Castellanos MN, Bardaji A, Menegon M, Mayor A, Desai M, Severini C, et al. Plasmodium vivax congenital malaria in an area of very low endemicity in Guatemala: implications for clinical and epidemiological surveillance in a malaria elimination context. Malar J. 2012;11:411.

39. Ho MF, Baker J, Lee N, Luchavez J, Ariey F, Nhem S, et al. Circulating antibodies against Plasmodium falciparum histidine-rich proteins 2 interfere with antigen detection by rapid diagnostic tests. Malar J. 2014;13:480.

40. Baker J, Ho MF, Pelecanos A, Gatton M, Chen N, Abdullah S, et al. Global sequence variation in the histidine-rich proteins 2 and 3 of Plasmodium falciparum: implications for the performance of malaria rapid diagnostic tests. Malar J. 2010;9:129.

41. Howard RJ, Uni S, Aikawa M, Aley SB, Leech JH, Lew AM, et al. Secretion of a malarial histidine-rich protein (Pf HRP II) from Plasmodium falciparuminfected erythrocytes. J Cell Biol. 1986;103:1269-77.

42. Wellems TE, Howard RJ. Homologous genes encode two distinct histidine-rich proteins in a cloned isolate of Plasmodium falciparum. Proc Natl Acad Sci USA. 1986;83:6065-9.

43. Lee N, Baker J, Bell D, McCarthy J, Cheng Q. Assessing the genetic diversity of the aldolase genes of Plasmodium falciparum and Plasmodium vivax and its potential effect on performance of aldolase-detecting rapid diagnostic tests. J Clin Microbiol. 2006;44:4547-9.

44. Cheng Q, Gatton ML, Barnwell J, Chiodini P, McCarthy J, Bell D, et al. Plasmodium falciparum parasites lacking histidine-rich protein 2 and 3: a review and recommendations for accurate reporting. Malar J. 2014;13:283.

45. Koita OA, Doumbo OK, Ouattara A, Tall LK, Konaré A, Diakité M, et al. False-negative rapid diagnostic tests for malaria and deletion of the histidine-rich repeat region of the hrp2 gene. Am J Trop Med Hyg. 2012;86:194-8.

46. Wurtz N, Briolant S, Lemarié D, Pommier de Santi V, Pascual A, Roodt T, et al. Delayed diagnosis of Plasmodium falciparum in a soldier in Uganda: false-positive rapid diagnostic test associated with reduced repeats in pfhrp2. Med Sante Trop. 2013;23:181-4.

47. Amoah LE, Abankwa J, Oppong A. Plasmodium falciparum histidine rich protein-2 diversity and the implications for PfHRP 2: based malaria rapid diagnostic tests in Ghana. Malar J. 2016;15:101.

48. Parr JB, Belson C, Patel JC, Hoffman IF, Kamthunzi P, Martinson F, et al. Estimation of Plasmodium falciparum transmission intensity in Lilongwe, Malawi, by microscopy, rapid diagnostic testing, and nucleic acid detection. Am J Trop Med Hyg. 2016;95:373-7.

49. Kozycki CT, Umulisa N, Rulisa S, Mwikarago El, Musabyimana JP, Habimana JP, et al. False-negative malaria rapid diagnostic tests in Rwanda: impact of Plasmodium falciparum isolates lacking hrp2 and declining malaria transmission. Malar J. 2017;16:123.

Ready to submit your research? Choose BMC and benefit from

- fast, convenient online submission

- thorough peer review by experienced researchers in your field

- rapid publication on acceptance

- support for research data, including large and complex data types

- gold Open Access which fosters wider collaboration and increased citations

- maximum visibility for your research: over $100 \mathrm{M}$ website views per year

At BMC, research is always in progress.

Learn more biomedcentral.com/submissions 